\title{
ECOC comparison exercise with identical thermal protocols after temperature offset correction - instrument diagnostics by in-depth evaluation of operational parameters
}

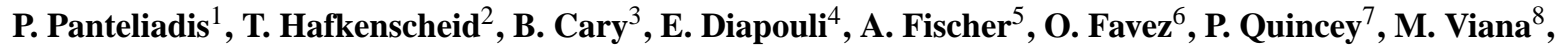 \\ R. Hitzenberger ${ }^{9}$, R. Vecchi ${ }^{10}$, D. Saraga ${ }^{11}$, J. Sciare ${ }^{12}$, J. L. Jaffrezo ${ }^{13}$, A. John ${ }^{14}$, J. Schwarz ${ }^{15}$, M. Giannoni ${ }^{16}$, \\ J. Novak ${ }^{17}$, A. Karanasiou ${ }^{8}$, P. Fermo ${ }^{18}$, and W. Maenhaut ${ }^{19}$ \\ ${ }^{1}$ Municipal Health Service (GGD) Amsterdam, Department of Air Quality, Amsterdam, the Netherlands \\ ${ }^{2}$ National Institute for Public Health and the Environment, Bilthoven, the Netherlands \\ ${ }^{3}$ Sunset Laboratory Inc, Tigard, Oregon, USA \\ ${ }^{4}$ National Center for Scientific Research "Demokritos", Institute of Nuclear \& Radiological Sciences \& \\ Technology, Energy \& Safety, Athens, Greece \\ ${ }^{5}$ EMPA - Swiss Federal Laboratories for Materials Science and Technology, Duebendorf, Switzerland \\ ${ }^{6}$ INERIS, Verneuil-en-Halatte, France \\ ${ }^{7}$ National Physical Laboratory, Teddington, UK \\ ${ }^{8}$ Institute for Environmental Assessment and Water Research (IDAEA-CSIC), Barcelona, Spain \\ ${ }^{9}$ Aerosolphysics and Environmental Physics, Faculty of Physics, Vienna, Austria \\ ${ }^{10}$ Department of Physics, Università degli Studi di Milano, Milan, Italy \\ ${ }^{11}$ Demokritos, National Center for Scientific Research, Environmental Research Laboratory, Athens, Greece \\ ${ }^{12}$ Laboratoire des Sciences du Climat et de l'Environnement (LSCE), CEA-CNRS-UVSQ, Gif-sur-Yvette, France \\ ${ }^{13}$ Univ. Grenoble Alpes, CNRS, LGGE, 38000 Grenoble, France \\ ${ }^{14}$ Institute for Energy and Environmental Technology e.V. Air Quality \& Sustainable Nanotechnology \\ Division, Duisburg, Germany \\ ${ }^{15}$ Institute of Chemical Process Fundamentals AS CR, Prague, Czech Republic \\ ${ }^{16}$ Istituto Nazionale di Fisica Nucleare (INFN), Sezione di Firenze, Florence, Italy \\ ${ }^{17}$ Czech Hydrometeorological Institute, Prague, Czech Republic \\ ${ }^{18}$ Department of Chemistry, Università degli Studi di Milano, Milan, Italy \\ ${ }^{19}$ Department of Analytical Chemistry, Ghent University, Gent, 9000, Belgium
}

Correspondence to: P. Panteliadis (ppanteliadis@ggd.amsterdam.nl)

Received: 6 June 2014 - Published in Atmos. Meas. Tech. Discuss.: 26 August 2014

Revised: 26 January 2015 - Accepted: 27 January 2015 - Published: 17 February 2015

\begin{abstract}
A comparison exercise on thermal-optical elemental carbon/organic carbon (ECOC) analysers was carried out among 17 European laboratories. Contrary to previous comparison exercises, the 17 participants made use of an identical instrument set-up, after correcting for temperature offsets with the application of a recently developed temperature calibration kit (Sunset Laboratory Inc, OR, US). Temperature offsets reported by participants ranged from -93 to $+100^{\circ} \mathrm{C}$ per temperature step. Five filter samples and two su-
\end{abstract}

crose solutions were analysed with both the EUSAAR2 and NIOSH870 thermal protocols.

$z$ scores were calculated for total carbon (TC); nine outliers and three stragglers were identified. Three outliers and eight stragglers were found for EC. Overall, the participants provided results between the warning levels with the exception of two laboratories that showed poor performance, the causes of which were identified and corrected through the course of the comparison exercise. The TC repeatabil- 
ity and reproducibility (expressed as relative standard deviations) were 11 and $15 \%$ for EUSAAR2 and 9.2 and $12 \%$ for NIOSH870; the standard deviations for EC were 15 and $20 \%$ for EUSAAR2 and 20 and $26 \%$ for NIOSH 870 .

TC was in good agreement between the two protocols, $\mathrm{TC}_{\mathrm{NIOSH} 870}=0.98 \times \mathrm{TC}_{\mathrm{EUSAAR} 2}\left(R^{2}=1.00\right.$, robust means). Transmittance (TOT) calculated EC for NIOSH870 was found to be $20 \%$ lower than for EUSAAR2, $\mathrm{EC}_{\mathrm{NIOSH} 870}=0.80 \times \mathrm{EC}_{\mathrm{EUSAAR} 2}\left(R^{2}=0.96\right.$, robust means). The thermograms and laser signal values were compared and similar peak patterns were observed per sample and protocol for most participants. Notable deviations from the typical patterns indicated either the absence or inaccurate application of the temperature calibration procedure and/or pre-oxidation during the inert phase of the analysis. Low or zero pyrolytic organic carbon (POC), as reported by a few participants, is suggested as an indicator of an instrument-specific pre-oxidation. A sample-specific preoxidation effect was observed for filter $\mathrm{G}$, for all participants and both thermal protocols, indicating the presence of oxygen donors on the suspended particulate matter. POC (TOT) levels were lower for NIOSH870 than for EUSAAR2, which is related to the heating profile differences of the two thermal protocols.

\section{Introduction}

Carbon in suspended atmospheric particulate matter usually falls into one of three wide categories, elemental carbon (EC), organic carbon (OC), and carbonate carbon (CC), the major fraction of inorganic carbon. Recently, more attention has been drawn to EC, due to its linkage to adverse health (Highwood and Kinnersley, 2006; Adar and Kaufman, 2007; Janssen et al., 2011, 2012) and climate effects (Jacobson, 2001; IPCC, 2007; Ramanathan and Carmichael, 2008). Several studies suggest that EC is a valid indicator for traffic emissions and include its analysis during monitoring campaigns (Lena et al., 2002; Schauer, 2003; Qadir et al., 2013; Panteliadis et al., 2014). A number of EC measurement techniques exist (Watson et al., 2005; Hitzenberger et al., 2006) with the thermal-optical transmittance (TOT) or reflectance (TOR) methods being broadly used in Europe and the USA. Several thermal protocols, which apply to TOT or TOR analysers, have been developed with NIOSH5040 (Birch and Cary, 1996), IMPROVE A (Chow et al., 2007) and EUSAAR2 (Cavalli et al., 2010) being the most commonly applied.

Even though quality assurance and quality control (QA/QC) procedures are of importance for any air quality measurements, no standard has yet been established in Europe for ECOC analysis (Chow et al., 2011). Following the EU Directive 2008/50/EC on ambient air and cleaner air for Europe, a technical report has been published (CEN TR
$16243,2011)$ and further work is currently being carried out towards method standardization within CEN-TC 264 (European Committee for Standardization) Working Group 35. Alongside the implementation of the technical report recommendations in the standard operation procedures of laboratories, comparison exercises are an important additional step towards QA/QC optimization.

The department of Air Quality of Public Health Service Amsterdam has been organizing laboratory comparison exercises for the past few years on thermal-optical ECOC analysers (Panteliadis, 2009a, 2011). To our knowledge, previous laboratory comparisons performed in Europe up to 2013 considered results derived from different protocols applied by each participant, usually NIOSH-like (CEN TR 16243, 2011) or EUSAAR2, on filter samples, limiting comparability of the performance of each laboratory. Numerous studies have demonstrated that ECOC analysis of ambient samples is sensitive to the temperature protocol selected (Sciare et al., 2003; Schauer et al., 2003; Chow et al., 2004; Cavalli et al., 2010; Zhi et al., 2011; Piazzalunga et al., 2011; Cheng et al., 2011, 2012). As a result, the temperature protocol selection may affect the conclusions obtained from comparisons between thermal-optical and optical (black carbon) analysis (Schmid et al., 2001; Schauer et al., 2003; ten Brink et al., 2004). Differences also occur with regard to the optical method used for the charring carbon correction, transmittance or reflectance, with the latter usually resulting in greater EC concentrations (Chow et al., 2004; Panteliadis, 2009b; Maenhaut et al., 2011).

The scope of this 2012 comparison exercise was to evaluate results based on an identical set-up for all participants using a lab ECOC analyser (Sunset Laboratory Inc., Tigard, OR, US). Generally in such exercises the same thermal protocol would be applied by all participants. However, the debate over the NIOSH-like and the EUSAAR2 thermal protocols is still ongoing in Europe, and the selection of a single temperature protocol would have been controversial and limiting. Comparison exercises performed so far have let the participants decide on the protocol applied (Panteliadis, 2009a, 2011; Emblico et al., 2012; Cavalli et al., 2012). As an alternative, we decided to stipulate the use of both NIOSH870, one of the latest versions of NIOSH-like protocols, and EUSAAR2 by each participant, providing additional information that could point out possible differences between the two protocols.

Each thermal protocol involves several temperature steps, and instrument-specific deviations from the desired temperature may alter the sample treatment and affect the analysis result (Chow et al., 2005). These deviations may originate from differences in type, age or installation of the heating coils used in each instrument. Since the introduction of a temperature calibration kit by the analyser's manufacturer (Sunset Laboratory Inc, OR, US) in early 2012, it has become possible to minimize such deviations. All participants using the lab ECOC analyser performed the calibration procedure and 
compensated for the temperature offsets before the comparison exercise analysis.

A common practice for total carbon (TC) calibrations and routine checks is the analysis of standard sucrose solutions. Such sucrose solutions were included in the current exercise in order to provide an insight into the degree of repeatability of these procedures, as well as to evaluate the practicability of adding a known volume of sucrose on the filter to be analysed. Unfortunately, the standard sucrose solutions can only provide information on calibration with pure OC. A suitable reference material consisting of pure EC is still lacking (Baumgardner et al., 2012). Finally, on top of the standard statistical analysis usually performed in such comparison exercises, a more in-depth evaluation of instrument specific parameters and characteristics, including the laser and the flame ionization detector (FID) signal as well as the peak distribution and calibration peak area, was carried out.

\section{Methods}

\subsection{Sample preparation and distribution}

A total of five $24 \mathrm{~h}$ PM loaded samples were collected for the exercise. Filters were selected with the intention of covering a common range of characteristics that occur in samples used for ECOC analysis. It is known, however, that the limited number of filters selected cannot be fully representative of the wide variety of ambient samples, which can be influenced by a number of parameters such as particle composition, pollution sources, seasonal and spatial variation.

The urban background sample from Amsterdam, The Netherlands, was collected with a $\mathrm{PM}_{10}$ high volume sampler (HVS) (ESM Andersen Instruments GmbH, Germany) on a Whatman QMA rectangular filter, $20.3 \times 25.4 \mathrm{~cm}$. The same filter type was used for the urban background sample from Athens, Greece, collected with a $\mathrm{PM}_{3}$ GS2312 BL HVS (Tisch Environmental, Ohio, US). Two $\mathrm{PM}_{2.5}$ suburban samples were collected in Duebendorf, Switzerland, with the use of a DHA80 sampler (Digitel Elektronik AG, Switzerland) on $150 \mathrm{~mm}$ diameter Pallflex Tissuquartz filters, on two consecutive dates. The same type of sampler and filter was used for the urban sample collected in Berne, Switzerland. The amount of transmitted laser light compared to the blank value, per filter, was reported by the organizing laboratory. An overview of the filters characteristics and sampling details is presented in Table 1 .

Upon receipt at GGD Amsterdam, all filters were stored at a temperature below $5^{\circ} \mathrm{C}$ till the distribution date. Four rectangular punches of $1 \times 1.5 \mathrm{~cm}^{2}$ per participant were cut out from different sections and increasing distance from the centre of each filter to avoid any sampling bias. For the same reason no punches were cut from the sampled area close to the edges of the filters. The punches were then stored in separate, closed, Petri-slide dishes, which were sent to each par- ticipant together with $30 \mathrm{~mL}$ vials of two standard sucrose solutions, S1 and S2, with nominal OC concentrations of 10.0 and $33.6 \mu \mathrm{g} 10 \mu \mathrm{L}^{-1}$, respectively. For the two participants using a field instrument four circular punches of $2 \mathrm{~cm}^{2}$ were prepared instead.

The homogeneity of PM loaded HVS filters, for the exact same samplers and filter media, had already been tested by GGD Amsterdam, and resulted in relative standard deviations of $11 \%$ for EC, $6 \%$ for OC and $5 \%$ for TC, for $150 \mathrm{~mm}$ Pallflex Tissuquartz HVS filters, and $10 \%$ for EC, $9 \%$ for OC and $6 \%$ for TC for Whatman QMA HVS filters (Table S1 in the Supplement). These values, however, represent only an indication of the expected within sample standard deviation for filter samples used in the current comparison exercise.

\subsection{ECOC analysis}

The EC, OC and TC concentrations in the PM samples and sucrose solutions were determined by all participants with the use either of a lab ECOC aerosol analyser (15 participants), or a semi-continuous ECOC field analyser (2 participants), all manufactured by Sunset Laboratory Inc. (Tigard, OR, US).

During the analysis, OC desorbs from the quartz fibre filter through progressive heating under a pure He stream, while a fraction of OC chars and forms pyrolysed organic carbon (POC). The sample is then heated in temperature steps under a mixture of $98 \% \mathrm{He}-2 \% \mathrm{O}_{2}$ ( $\mathrm{HeOx}$ phase) and the POC and EC are desorbed. In order to correct for the pyrolysis effect, the analyser utilizes a $658 \mathrm{~nm}$ laser beam, reflected and/or transmitted through the filter media. The split point, which separates OC from EC and compensates for POC, is determined when the laser signal returns to its initial value. $\mathrm{OC}, \mathrm{EC}$ and POC are catalytically converted, initially to $\mathrm{CO}_{2}$ and then to $\mathrm{CH}_{4}$, which is quantified with the use of an FID. The time necessary for the gaseous compounds desorbed to reach the FID unit from the filter media is defined as transit time and is an instrument-specific parameter. A fixed volume of calibration gas $\left(5 \% \mathrm{CH}_{4}\right.$ in helium) is injected in the instrument at the end of each analysis and the responding FID signal forms the calibration peak. The area of the calibration peak together with a calibration constant are used for the calculation of the sample concentration. The calibration constant depends on the calibration gas fixed volume analysed per run, which is set by the manufacturer, and is instrumentspecific.

The operating parameters of the analyser vary with the thermal protocol used during analysis. The two protocols mainly used in Europe, NIOSH870 and EUSAAR2, were applied by all participants for the analysis of the sample punches provided. Before analysis, most participants calibrated their instruments for temperature offsets at each step, with the use of a calibration kit. The temperature calibration procedure has to be applied for each thermal protocol separately, since they vary in the number of steps, tempera- 
Table 1. PM loaded filters description and sampling details.

\begin{tabular}{|c|c|c|c|c|c|c|c|c|c|}
\hline $\begin{array}{l}\text { Filter } \\
\text { code }\end{array}$ & Location & $\begin{array}{l}\text { Site } \\
\text { description }\end{array}$ & $\begin{array}{l}\mathrm{PM} \\
\text { fraction } \\
\left(\mu \mathrm{g} \mathrm{m}^{-3}\right)\end{array}$ & Filter type & Date & $\begin{array}{l}\text { Volume } \\
\left(\mathrm{m}^{3}\right)\end{array}$ & $\begin{array}{l}\text { Sampling } \\
\text { time (h) }\end{array}$ & Instrument & $\begin{array}{l}\% \text { Transmitted } \\
\text { laser intensity } \\
\text { compared to blank }\end{array}$ \\
\hline \multirow[t]{2}{*}{ A } & \multirow[t]{2}{*}{ Athens } & Urban & $3.0(\mathrm{NA})^{2}$ & $\begin{array}{l}\text { Whatman } \\
\text { QMA }\end{array}$ & 1 Mar 2012 & 1411 & 24 & Andersen GS2312 & \multirow[t]{2}{*}{38} \\
\hline & & background & & $20.3 \times 25.4 \mathrm{~cm}$ & & & & BL HVS & \\
\hline B & Berne & Urban & $2.5(72.8)$ & $\begin{array}{l}\text { Pallflex } \\
\text { Tissuquartz } \\
150 \mathrm{~mm}\end{array}$ & 9 Feb 2012 & 720 & 24 & Digitel DHA80 & 14 \\
\hline $\mathrm{D}$ & Duebendorf & Suburban & $2.5(7.8)$ & $\begin{array}{l}\text { Pallflex } \\
\text { Tissuquartz } \\
150 \mathrm{~mm}\end{array}$ & $15 \mathrm{Feb} 2012$ & 720 & 24 & Digitel DHA80 & 51 \\
\hline G & Amsterdam & Urban & $10(24.4)$ & $\begin{array}{l}\text { Whatman } \\
\text { QMA }\end{array}$ & $13 \operatorname{Dec} 2005^{1}$ & 1625 & 24 & Andersen/GMW & 32 \\
\hline & & background & & $20.3 \times 25.4 \mathrm{~cm}$ & & & & $1200 \mathrm{HVS}$ & \\
\hline $\mathrm{U}$ & Duebendorf & Suburban & $2.5(37.0)$ & $\begin{array}{l}\text { Pallflex } \\
\text { Tissuquartz } \\
150 \mathrm{~mm}\end{array}$ & 14 Feb 2012 & 720 & 24 & Digitel DHA80 & 23 \\
\hline
\end{tabular}

${ }^{1}$ Stored below $5{ }^{\circ} \mathrm{C}$ till the distribution date ${ }^{2}$ not available.

Table 2. Details of the two thermal protocols applied by the participants and observed temperature offset range per step.

\begin{tabular}{lccc|ccc}
\hline & \multicolumn{3}{c}{ NIOSH870 } & \multicolumn{3}{c}{ EUSAAR2 } \\
\cline { 2 - 6 } Carrier gas & $\begin{array}{c}\text { Time } \\
(\mathrm{s})\end{array}$ & $\begin{array}{c}\text { Temperature } \\
\left({ }^{\circ} \mathrm{C}\right)\end{array}$ & $\begin{array}{c}\text { Range } T \text { offsets } \\
\left({ }^{\circ} \mathrm{C}\right)\end{array}$ & $\begin{array}{c}\text { Time } \\
(\mathrm{s})\end{array}$ & $\begin{array}{c}\text { Temperature } \\
\left({ }^{\circ} \mathrm{C}\right)\end{array}$ & $\begin{array}{c}\text { Range } T \text { offsets } \\
\left({ }^{\circ} \mathrm{C}\right)\end{array}$ \\
\hline Purge time & 10 & - & - & 10 & - & - \\
Helium & 80 & 310 & $(-58-46)$ & 120 & 200 & $(-71-100)$ \\
Helium & 80 & 475 & $(-51-63)$ & 150 & 300 & $(-67-54)$ \\
Helium & 80 & 615 & $(-50-70)$ & 180 & 450 & $(-60-47)$ \\
Helium & 110 & 870 & $(-68-81)$ & 180 & 650 & $(-58-51)$ \\
OC analysis time & 360 & & & 640 & & - \\
\hline Helium (Oven cool) & 45 & 550 & $(-93-65)$ & 30 & - & $(-68-49)$ \\
Oxygen in helium $(2 \%)$ & 45 & 550 & $(-93-65)$ & 120 & 500 & $(-59-40)$ \\
Oxygen in helium $(2 \%)$ & 45 & 625 & $(-75-67)$ & 120 & 550 & $(-68-51)$ \\
Oxygen in helium $(2 \%)$ & 45 & 700 & $(-65-70)$ & 70 & 700 & $(-85-64)$ \\
Oxygen in helium $(2 \%)$ & 45 & 775 & $(-70-72)$ & 80 & 850 & - \\
Oxygen in helium $(2 \%)$ & 45 & 850 & $(-76-73)$ & - & - & - \\
Oxygen in helium $(2 \%)$ & 110 & 870 & $(-80-63)$ & - & - & \\
EC analysis time & 380 & & & 390 & & \\
\hline Calibration & 120 & & & 110 & & min and 30 s \\
Total analysis time & 14 min and 20s & & &
\end{tabular}

ture and duration. The differences between EUSAAR2 and NIOSH870, together with the observed offset ranges, are illustrated in Table 2.

Two participants performed the temperature calibration only for the EUSAAR2 protocol while one did not apply it at all. Two participants used the temperature offsets as found for the GGD instrument. The temperature calibration procedure was not applicable for the field analysers. A wide range of temperature offsets was observed between participants $(-93$ to $+100^{\circ} \mathrm{C}$ ), and also between different temperature steps for the same analyser (up to $86^{\circ} \mathrm{C}$ ). An overview of the thermal protocols, optical method and temperature offsets applied by each participant can be found in Table 3. The heating profile of each analyser after the temperature offset correction was also recorded for both protocols (Figs. S1-S2 in the Supplement).

Two of the four punches received by each participant were analysed with NIOSH870 and two with EUSAAR2, whereas triplicate analyses with both protocols were applied for the two sucrose solutions. 
Table 3. Thermal protocols used for replicate analysis, optical method applied and temperature offset range per laboratory.

\begin{tabular}{|c|c|c|c|}
\hline Laboratory & Protocols - replicates & Optical method & $T$ offset range $\left({ }^{\circ} \mathrm{C}\right)$ \\
\hline 1 & NIOSH870 - EUSAAR2 & TOT - TOR & $(-58--10)$ \\
\hline 2 & NIOSH870 - EUSAAR2 & TOT - TOR & $(-65--6)$ \\
\hline 3 & NIOSH930 ${ }^{\mathrm{a}}$ - EUSAAR2 & TOT - TOR & $(-87-21)$ \\
\hline 4 & NIOSH870 - EUSAAR2 & TOT & $(-86--50)$ \\
\hline 5 & NIOSH-like ${ }^{b}$ - EUSAAR2 & TOT - TOR & $(-55--5)$ \\
\hline 6 & NIOSH870 - EUSAAR2 & TOT - TOR & $(-93--7)$ \\
\hline 7 & NIOSH870 - EUSAAR2 $^{\mathrm{c}}$ & TOT - TOR & $(-60--24)$ \\
\hline 8 & NIOSH870 - EUSAAR2 & TOT - TOR & $(30-81)$ \\
\hline 9 & NIOSH870 - EUSAAR2 & TOT & $(-73--31)$ \\
\hline 10 & NIOSH870 - EUSAAR2 & TOT - TOR & $(-12-3)^{\mathrm{d}}$ \\
\hline 11 & NIOSH870 - EUSAAR2 & TOT & $(-64--16)^{\mathrm{e}}$ \\
\hline 12 & NIOSH870 - EUSAAR2 & TOT & $(-59--26)$ \\
\hline 13 & NIOSH870 - EUSAAR2 & TOT - TOR & $(33-100)^{\mathrm{d}}$ \\
\hline 14 & NIOSH870 - EUSAAR2 & TOT - TOR & $(-58--10)^{\mathrm{d}}$ \\
\hline 15 & NIOSH870 - EUSAAR2 & TOT & Not performed \\
\hline 16 & NIOSH870 - EUSAAR2 & TOT & Not applicable ${ }^{\mathrm{g}}$ \\
\hline 17 & NIOSH870 - EUSAAR2 ${ }^{\text {f }}$ & TOT & Not applicableg \\
\hline
\end{tabular}

a NIOSH930 applies an additional heating step at the end of the $\mathrm{HeOx}$ phase at $930^{\circ} \mathrm{C}$ for $120 \mathrm{~s} ;{ }^{\mathrm{b}} 890^{\circ} \mathrm{C}$ applied at the last heating step instead of $870^{\circ} ; \mathrm{c}$ limited number of filters analysed in EUSAAR2; ${ }^{\mathrm{d}}$ applied only for EUSAAR2 protocol; ${ }^{\mathrm{e}}$ no calibration performed, GGD offsets applied instead; ${ }^{\mathrm{f}}$ limited sample set analysed; $\mathrm{g}$ field analyser.

\subsection{Statistical analysis}

\subsubsection{Laboratory performance}

The robust means for the filter samples, derived from the means of replicate measurements, were calculated following ISO 13528 (2005, Annex C). Due to the lack of a certified reference material, the robust mean for each sample was taken as the consensus reference value. The $z$ scores were calculated for TC and EC, and for EUSAAR2 and NIOSH870, in order to evaluate the capacity of each laboratory to comply with the selected fit-for-purpose standard deviation, using the equation:

$z=(x-X) / \sigma$,

where $x$ is the result of the participant (average of duplicate analyses), $X$ is the robust mean, $\sigma$ is the fit-for-purpose standard deviation.

Due to the lack of certified reference methods for ECOC measurements, the fit-for-purpose standard deviations were arbitrarily selected, based on experience and the desired level for compliance purposes: $8.3 \%$ for TC and $25 \%$ for EC. The $8.3 \%$ for TC roughly corresponds to a range of $\pm 25 \%$ into which all results should fall. $z$ scores between the warning levels, -2 and +2 , were considered as indications of satisfactory performance, while $z$ scores between the warning and the action levels, -3 and +3 , were considered questionable. All $z$ scores outside the action levels range were considered as indications of unsatisfactory performance.

\subsubsection{Method performance}

The laboratory performance was initially evaluated graphically, by sucrose solutions plots and Mandel's $h$ and $k$ statistics for TC and EC results pooled for both EUSAAR2 and NIOSH870. The Mandel's $h$ statistic indicated the between-laboratory consistency while Mandel's $k$ indicated the within-laboratory consistency. Laboratory results reported above the critical value at $1 \%$ significance level were identified as possible outliers, and between the critical values of 1 and $5 \%$ significance level as stragglers (ISO 5725-2, 1994). Grubbs' and Cochran's statistical outlier tests were also applied and outliers were removed from the data set for the calculations of the corrected robust means, repeatability and reproducibility relative standard deviations (ISO 5725-2, 1994).

\section{Results}

\subsection{Data evaluation}

All results, as reported by the participating laboratories, namely TC, EC, OC and EC/TC for both TOT and TOR are given in the Supplement, Tables S2-S8. The reported TC concentrations ranged on average from 10.1 to $79.0 \mu \mathrm{g} \mathrm{cm}{ }^{-2}$, while EC ranged from 0.9 to $11.5 \mu \mathrm{g} \mathrm{cm}^{-2}$ (TOT) and 1.8 to $17.5 \mu \mathrm{g} \mathrm{cm}^{-2}$ (TOR), depending on the thermal protocol used. 

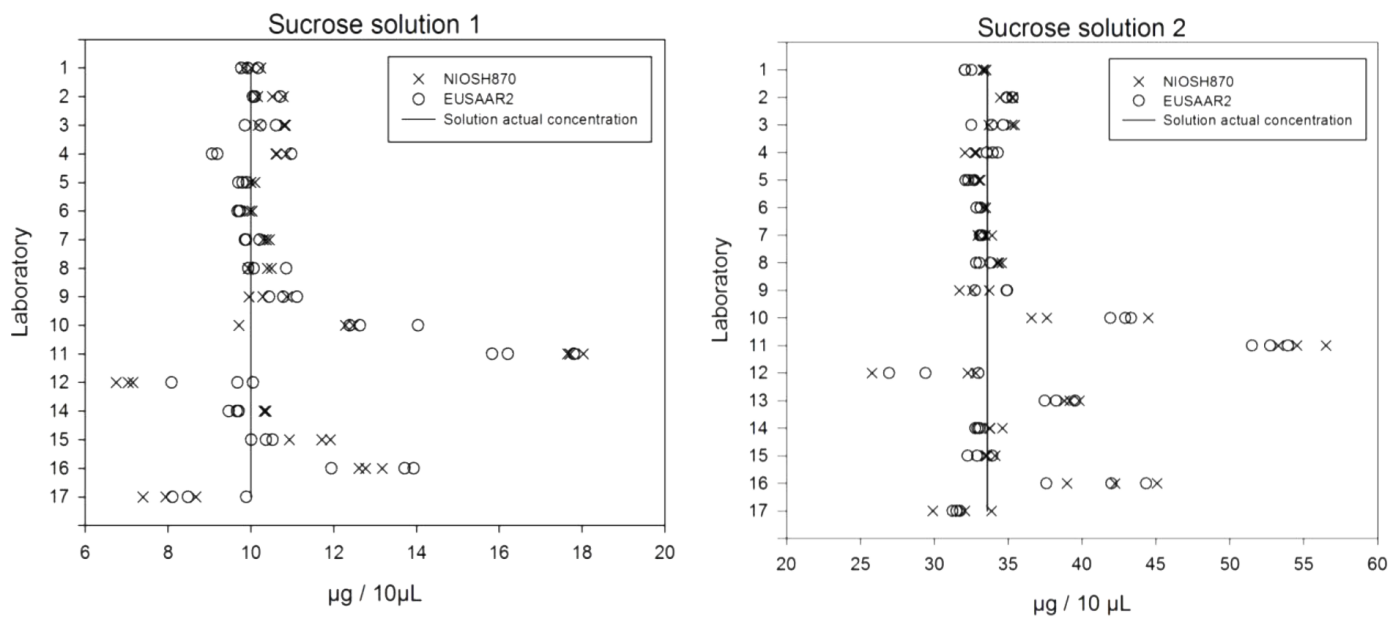

Figure 1. Triplicate sucrose solution analysis (S1 and S2) per protocol and participant. S1 and S2 concentrations of 10.0 and $33.6 \mu \mathrm{g} 10 \mu \mathrm{L}^{-1}$, respectively.

\subsection{Laboratory performance}

An initial overview of deviation in performance can be gained from Fig. 1, which presents graphically the reported results of all participants for the two sucrose solutions.

The $z$ scores for the EC and TC results of the filter samples, calculated separately for EUSAAR2 and NIOSH870, are shown in Figs. S3-S6 in the Supplement. For TC, seven outliers and three stragglers were identified for EUSAAR2, and 12 outliers for NIOSH870, all of which were reported by three participants. For EC, one outlier and four stragglers were identified for EUSAAR2 while two outliers and four stragglers were identified for NIOSH870. All outliers and stragglers were reported by three participants, two of whom were the same as those with high TC $z$ scores.

\subsection{Method performance}

Figure S7, in the Supplement, presents the Mandel's $k$ statistic for the sucrose solutions, with the EUSAAR2 and NIOSH870 TC pooled results. Five outliers were identified, two for laboratory 10 , two for 12 , and one for 16 . The outliers of laboratories 10 and 12 were confirmed by Cochran's test while the one of laboratory 16 was identified as a straggler. The Mandel's $h$ statistic values for the sucrose solutions can be found in Fig. S8 in the Supplement. Two outliers were found for laboratory 11, confirmed also by Grubbs' test.

Figure S9, in the Supplement, presents the Mandel's $k$ statistic values for the loaded filters, for EUSAAR2 and NIOSH870 pooled TC results. Seven outliers were identified, three for laboratory 12 , two for 16 , and one for each of 10 and 11. Two stragglers were also identified, one for laboratory 13, and one for 16 . Two out of the three outliers of laboratory 12 , both for 16 and the one for 10 were confirmed by Cochran's test while the one for laboratory 11 was identified as a straggler.
The Mandel's $h$ statistic values for the loaded filters, EUSAAR2 and NIOSH870 pooled TC results, can be found in Fig. S10 in the Supplement. Five outliers were identified, all for laboratory 11 , four of which were indicated as stragglers by Grubbs' test. Four stragglers were observed, all for laboratory 10 , one of which was confirmed by Grubbs' test.

Similarly to Fig. S9, Fig. S11 presents the Mandel's $k$ statistic values for pooled EC (TOT) results of the loaded filters. Three outliers and two stragglers were identified; one outlier for each of laboratories 3, 4 and 16, and one straggler for 15 and 16. The three outliers were also confirmed by Grubbs' test. Figure S12, in the Supplement, presents the Mandel's $h$ statistic values for the filters pooled EC (TOT) results. Four outliers and three stragglers were identified in total. Laboratories 10 and 11 reported two outliers and one straggler each while one straggler was reported by laboratory 3 and one by 8 . The Grubbs' test confirmed all outliers and stragglers for laboratories 10 and 11 but not the stragglers for 3 and 8.

The normalized mean values and the repeatability and reproducibility relative standard deviations for the filter samples were calculated initially for the full data set and then after discarding the verified outliers. Table S9 in the Supplement shows the values separated by protocol for TC, while Table S10, also in the Supplement, shows the same for EC. For the corrected results, the repeatability relative standard deviation for TC was $11 \%$ for EUSAAR2 and $9 \%$ for NIOSH870. The reproducibility standard deviation was $15 \%$ for EUSAAR2 and $12 \%$ for NIOSH870. For EC, the repeatability standard deviation was $15 \%$ for EUSAAR2 and $20 \%$ for NIOSH870. The reproducibility standard deviation was $20 \%$ for EUSAAR2 and $26 \%$ for NIOSH870. All standard deviations were higher for EC than TC. All standard deviation values were higher for EUSAAR2 for TC, while the opposite held for EC. 
The TC robust means, repeatability and reproducibility standard deviations per filter were calculated for pooled EUSAAR2 and NIOSH870 results (Table S11 in the Supplement). TC robust means ranged from 9.7 to $77.0 \mu \mathrm{g} \mathrm{cm}{ }^{-2}$. Repeatability ranged from 9 to $12 \%$ and reproducibility from 11 to $15 \%$ per filter.

No significant differences were observed between EUSAAR2 and NIOSH870 for TC, where $\mathrm{TC}_{\text {NIOSH870 }}=0.97 \times \mathrm{TC}_{\text {EUSAAR2 }} \quad\left(R^{2}=0.96\right) \quad$ for loaded PM filters and $\mathrm{TC}_{\mathrm{NIOSH}} 870=1.00 \times \mathrm{TC}_{\text {EUSAAR2 }}$ $\left(R^{2}=0.98\right)$ for sucrose solution raw data (Fig. S13 in the Supplement). When the raw data for EC for the loaded filters were compared, EUSAAR2 was found to report higher values, $\mathrm{EC}_{\mathrm{NIOSH} 870}=0.73 \times \mathrm{EC}_{\mathrm{EUSAAR} 2}\left(R^{2}=0.72\right)$ for TOT. For TOR, EUSAAR2 and NIOSH870 were closer, $\mathrm{EC}_{\mathrm{NIOSH} 870}=0.85 \times \mathrm{EC}_{\text {EUSAAR2 }} \quad\left(R^{2}=0.69\right) \quad$ (Fig. S14 in the Supplement). For both protocols the use of TOR resulted in notably higher EC concentrations than TOT, $64 \%$ higher $\left(R^{2}=0.52\right)$ for EUSAAR2 and $113 \%$ higher $\left(R^{2}=0.44\right)$ for NIOSH870 $(N=89)$. All zero NIOSH870 EC concentrations shown in the graphs were reported by a single participant due to laser failure. Note that not all participants reported data for both TOT and TOR, as a result of instrument configuration.

When the robust means were used for the same plots $\mathrm{TC}_{\text {NIOSH870 }}=0.98 \times \mathrm{TC}_{\text {EUSAAR2 }}\left(R^{2}=1.00\right)$ for loaded $\mathrm{PM}$ filters and $\mathrm{EC}_{\mathrm{NIOSH} 870}=0.80 \times \mathrm{EC}_{\mathrm{EUSAAR} 2}\left(R^{2}=\right.$ $0.96)$ for TOT and $\mathrm{EC}_{\mathrm{NIOSH} 870}=1.15 \times \mathrm{EC}_{\mathrm{EUSAAR} 2}\left(R^{2}=\right.$ 0.95 ) for TOR were found (Fig. S15 in the Supplement).

\subsection{EUSAAR2 and NIOSH870 comparison}

Table 4 shows the ranges of split points reported by the participants for each filter sample, protocol and optical method used. In all cases the split points in EUSAAR2 occur later than in NIOSH870, due to the extended overall duration of EUSAAR2. The split point defined by TOR appears to occur earlier than that defined by TOT. In most cases the overall split point range among participants for the same filter is $\sim 100 \mathrm{~s}$, except for sample A, where it extends up to $200 \mathrm{~s}$, and sample G, up to $300 \mathrm{~s}$. Both samples A and G were collected on the same filter media, Whatman QMA, while B, $\mathrm{D}$ and $\mathrm{U}$ are on Pallflex Tissuquartz, which may relate to the observed deviation. Note that Whatman QMA is thicker, $450 \mu \mathrm{m}$, than Pallflex Tissuquartz, $432 \mu \mathrm{m}$, as reported by their manufacturers.

The relative standard deviations of the calibration area of each instrument together with the calibration constant, the transit time and the atmospheric pressure are presented in Table 5 . The calibration area relative standard deviations range from 1.4 to $24.6 \%$ and the calibration constant from 17.1 to 28.7. Fluctuations of the atmospheric pressure of the laboratory may be of influence to the gas flows and consequently to the calibration area. The fluctuations in atmospheric pressure, as measured by each instrument, were in most cases
Table 4. Split point ranges as reported by all participants, per sample, protocol and optical method.

\begin{tabular}{llll}
\hline \multirow{2}{*}{ Sample } & \multirow{2}{*}{ Protocol } & \multicolumn{2}{c}{ Split point range (s) } \\
\cline { 3 - 4 } & & Transmittance & Reflectance \\
\hline \multirow{2}{*}{ A } & EUSAAR2 & $(745-941)$ & $(772-862)$ \\
& NIOSH870 & $(434-531)$ & $(344-518)$ \\
B & EUSAAR2 & $(826-932)$ & $(772-886)$ \\
& NIOSH870 & $(427-518)$ & $(414-499)$ \\
D & EUSAAR2 & $(875-997)$ & $(840-982)^{\mathrm{a}}$ \\
& NIOSH870 & $(490-593)^{\mathrm{b}}$ & $(467-569)$ \\
$\mathrm{G}$ & EUSAAR2 & $(582-859)$ & $(736-888)$ \\
& NIOSH870 & $(302-524)$ & $(324-521)$ \\
$\mathrm{U}$ & EUSAAR2 & $(808-977)$ & $(809-898)^{\mathrm{c}}$ \\
& NIOSH870 & $(471-561)$ & $(347-534)$ \\
\hline
\end{tabular}

One participant reported clearly outlying split points: ${ }^{\mathrm{a}} 1073 \mathrm{~s} ;{ }^{\mathrm{b}} 819 \mathrm{~s}$; c $991 \mathrm{~s}$.

within a range of $10 \mathrm{mmHg}$. Nevertheless, five instruments reported values significantly lower than expected, between 374 and $427 \mathrm{mmHg}$, indicating a possible malfunction or absence of the pressure sensor, which results in the instrument recording an offset value.

The transit time ranges from 6 to $15 \mathrm{~s}$. An incorrect transit time will result in a shift of the split point and thus incorrect concentration values for the $\mathrm{OC}$ and $\mathrm{EC}$ fractions. A check procedure for the transit time is available from the analyser's manufacturer but its application was not included in the prerequisites of the current comparison exercise.

Thermograms for sample A from different participants using NIOSH870 showed a similar peak distribution with a high first peak, low second, third and fourth peaks and a high fifth peak when POC and EC evolve. The split point range covers almost the whole fifth peak and no EC is measured after $600 \mathrm{~s}$ (Fig. 2). The EUSAAR2 thermograms for sample A show more variation in the peak distribution than the NIOSH870 thermograms, but in general start with a high first peak, with the second, third, and fourth peaks gradually reducing in size. Then a high fifth peak is observed when the POC and EC desorb, followed by a gradual decrease in the sixth and seventh peaks. EC seems to desorb up to the very end of the analysis (Fig. 3). Similar observations can be made for filter B (Figs. S16-S17).

For the sucrose solutions, with the exception of a couple of participants, there is good agreement in the peak distribution, which is better for NIOSH870 than EUSAAR2 (Figs. 4, 5). For NIOSH870, most of the OC is evolved in the first peak, followed by low second, third and fourth peaks and a slightly higher fifth peak for the POC. Almost no carbon is measured after $600 \mathrm{~s}$. For EUSAAR2, most of the participants reported a high second peak and lower third, fourth, and fifth peaks. The POC evolves in a wide time frame from 700 s until the end of the analysis in some cases. Four participants report a medium to low first peak, while for the rest of the partici- 
Table 5. Relative standard deviations (\% rSD) of calibration area for all analyses per participant. Instrument specific characteristics, calibration constant, transit time and atmospheric pressure.

\begin{tabular}{lcccc}
\hline Laboratory & $\begin{array}{c}\text { \% rSD } \\
\text { calibration area }\end{array}$ & $\begin{array}{c}\text { Calibration } \\
\text { constant }\end{array}$ & $\begin{array}{c}\text { Transit time } \\
\text { (seconds) }\end{array}$ & $\begin{array}{c}\text { Atmospheric pressure } \\
(\mathrm{mmHg})\end{array}$ \\
\hline 1 & 1.9 & 23.4 & 11 & $(729.3-744.1)$ \\
2 & 2.0 & 19.9 & 11 & $(426.1-426.9)$ \\
3 & 14.9 & 24.7 & 8 & $(751.4-763.6)$ \\
4 & 1.4 & 17.1 & 7 & $(741.4-747.7)$ \\
5 & 2.8 & 24.6 & 13 & $(748.3-750.9)$ \\
6 & 3.0 & 24.6 & 12 & $(725.8-739.6)$ \\
7 & 2.3 & 20.9 & 15 & $(761.7-775.0)$ \\
8 & 1.4 & 25.5 & 7 & $(384.3-384.4)$ \\
9 & 14.4 & 23.4 & 6 & $(742.2-746.5)$ \\
10 & 14.6 & 20.1 & 12 & $(375.4-375.7)$ \\
11 & 4.6 & 28.7 & 12 & $(774.6-785.0)$ \\
12 & 24.6 & 18.6 & 11 & $(374.6-374.9)$ \\
13 & 8.9 & 22.0 & 14 & $(382.0-382.6)$ \\
14 & 10.2 & 22.3 & 13 & $(723.5-726.3)$ \\
15 & 3.8 & 22.5 & 7 & $(719.7-731.4)$ \\
\hline
\end{tabular}

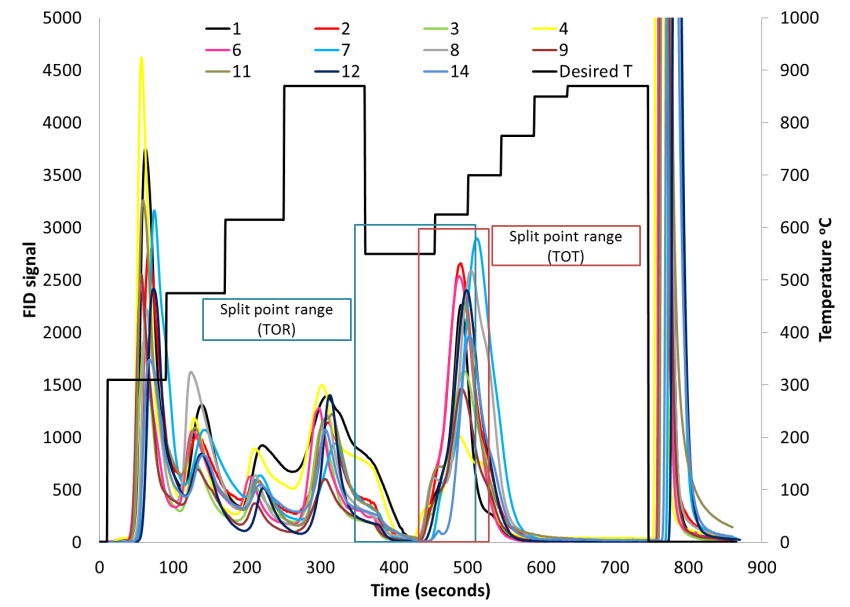

Figure 2. Thermograms of ECOC analysis on PM loaded quartz fibre filter (A sample), by NIOSH870 for all participants.

pants it is not present. This first peak may be an indication of contamination due to handling during the sucrose analysis procedure. Such contamination would not be visible with the NIOSH 870 protocol as it would be masked by the already high first peak.

Figures 6 and 7 show the concentrations for each temperature step and protocol for samples A and B. In most cases POC and EC are lower for NIOSH870 compared to EUSAAR2. Some participants reported limited or no POC for sample A, suggesting that oxygen may have been present in the system during the inert phase. This became less visible for sample B, where concentrations were higher. For sucrose, most participants report the greatest fraction of $\mathrm{OC}$ at the first temperature step (OC1) for NIOSH870 and the second

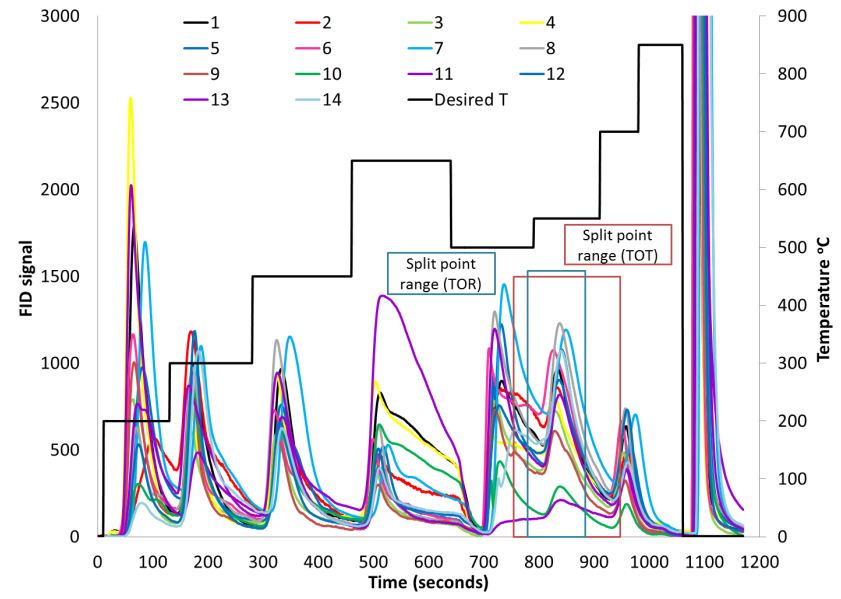

Figure 3. Thermograms of ECOC analysis on PM loaded quartz fibre filter (A sample), by EUSAAR2 for all participants.

(OC2) for EUSAAR2 (Fig. 8). Similarly to filter A, some participants report low or no POC for the sucrose solutions, indicating instrument specific pre-oxidation.

Figures 9-12 show the laser transmittance signal plots for each participant for the analysis of samples $A$ and $G$ for both EUSAAR2 and NIOSH870. A high frequency noise to the laser signal can be observed in all cases for laboratory 5 , and non-systematic deviating behaviour for laboratories 4 and 11 . Laboratory 12 shows a low frequency noise for all samples. A ramping up of the laser signal before the $\mathrm{HeOx}$ phase, indicating pre-oxidation, is seen occasionally for several laboratories, but mostly for 1, 3 and 4 . The same ramping effect in the He phase, seen by almost all participants for filter G, indicates that in this case the pre-oxidation is not instrument spe- 


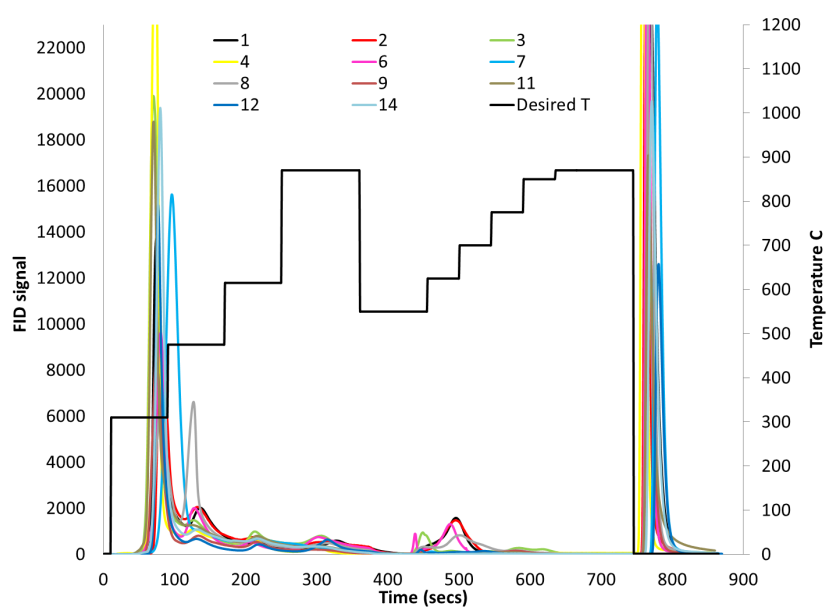

Figure 4. Thermograms of ECOC analysis on standard sucrose solution (S2), by NIOSH870 for all participants.

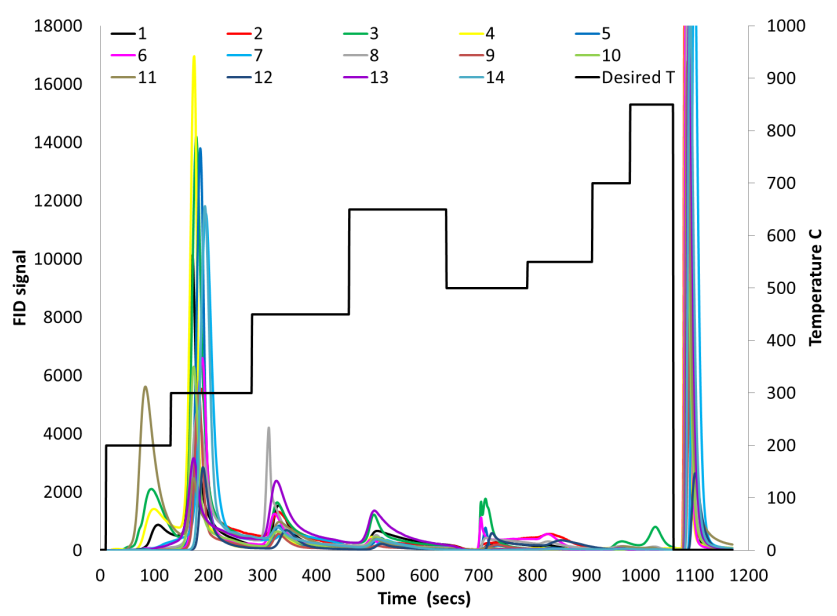

Figure 5. Thermograms of ECOC analysis on standard sucrose solution (S2), by EUSAAR2 for all participants.

cific but sample related. A possible explanation may be the presence of metals and/or metal oxides (Wang et al., 2010). The laser transmittance signal for a blank filter, as derived from the values at the end of each analysis, covers a wide range among the participants, from $\sim 1000$ to $\sim 20000$. The respective figures for the laser reflectance signal plots can be found in the Supplement, Figs. S18-S21. However, no observations similar to those for the transmittance signal can be drawn.

A limited number of participants reported data from instrument blank analysis. Supplement Figs. S22 and S23 show the laser signal, TOT and TOR results, for EUSAAR2 and NIOSH870 for the blank filters. The laser signal is stable throughout each analysis with the exception of laboratory 3 , showing no dependence on the oven temperature.

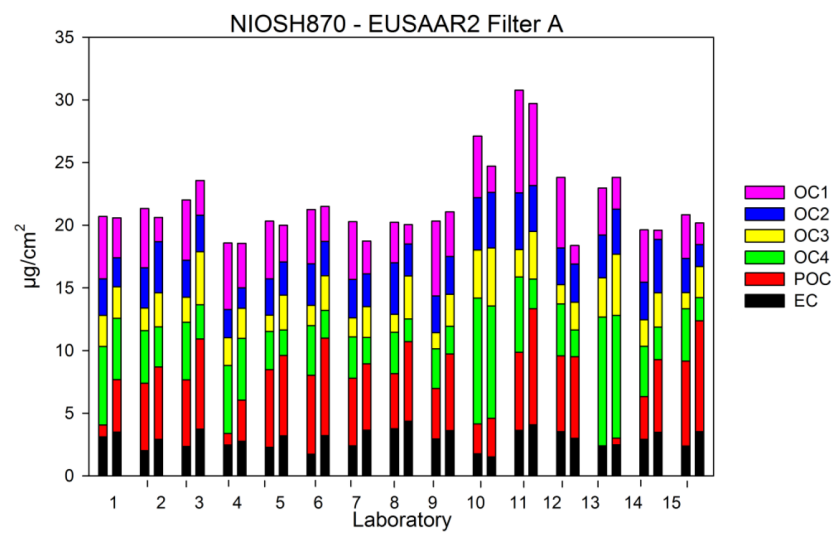

Figure 6. OC, POC and EC (TOT) concentrations $\left(\mu \mathrm{g} \mathrm{cm}^{-2}\right)$ per temperature step and protocol for PM loaded quartz fibre filter (sample A).

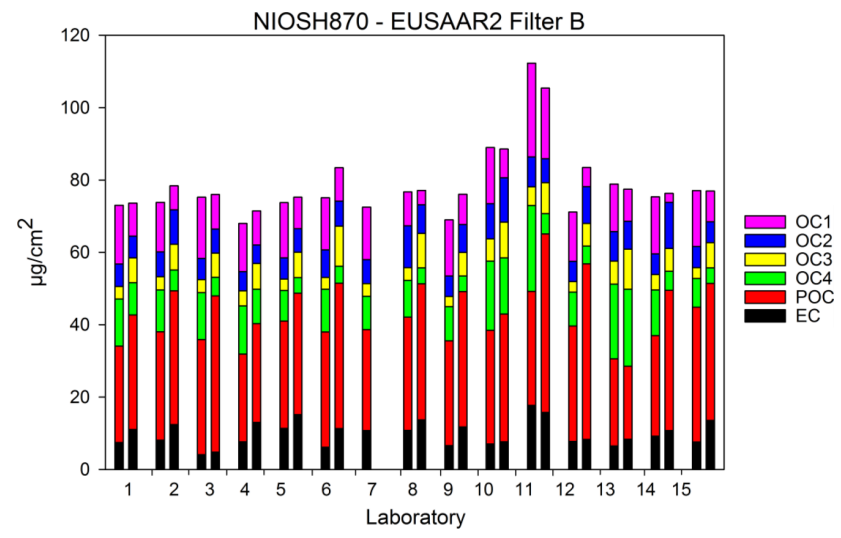

Figure 7. OC, POC and EC (TOT) concentrations $\left(\mu \mathrm{g} \mathrm{cm}^{-2}\right)$ per temperature step and protocol for PM loaded quartz fibre filter (sample B).

\section{Discussion}

Based on $z$ scores for TC, two laboratories showed poor performance, reporting results with a significant positive systematic error; seven outliers and two stragglers for laboratory 10 and ten outliers for laboratory 11 (Figs. S3, S4). In the course of this work the causes of the observed deviations were identified and corrected. Laboratory 16, which used a semi-automated field analyser, reported two outliers and one straggler, while the rest of participants were within the warning levels. Similar observations can be made for the EC $z$ scores, with laboratory 10 reporting one outlier and three stragglers, laboratory 11 one outlier and four stragglers, and laboratory 3 one outlier and one straggler. It should be noted that different fit-for-purpose deviations were selected as levels of satisfactory performance for TC $(8.3 \%)$, which is thermally defined, and EC (25\%) which is both thermally and optically defined. 


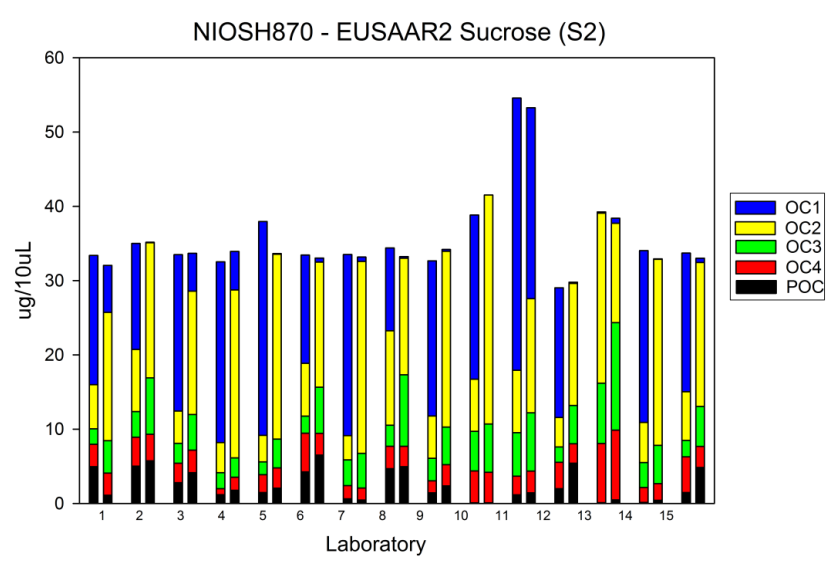

Figure 8. OC, POC and EC (TOT) concentrations ( $\left.\mu \mathrm{g} 10 \mu \mathrm{L}^{-1}\right)$ per temperature step and protocol for sucrose solution (S2).

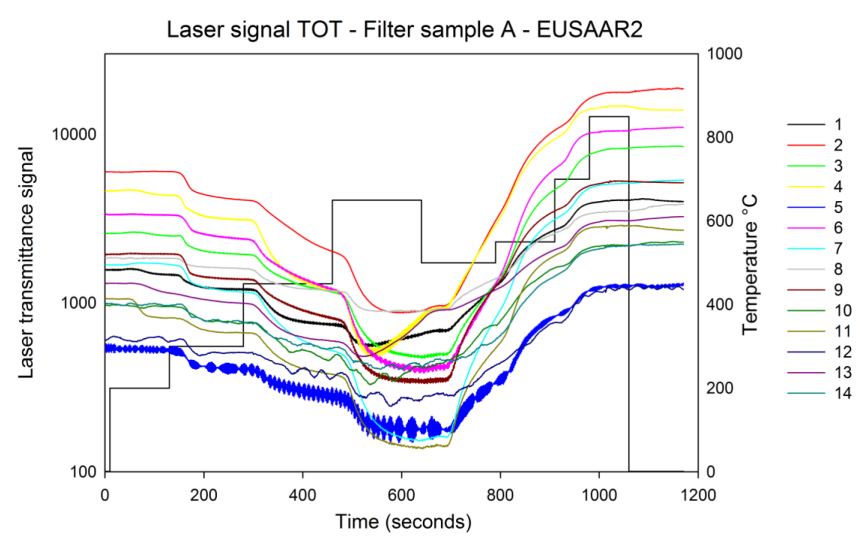

Figure 9. Laser transmittance signal during filter sample A analysis with the use of EUSAAR2 thermal protocol for all laboratories.

As seen in Fig. 1, the analyses of sucrose solutions in comparison exercises can serve as an indicator of poorly conducted TC calibration or unsatisfactory performance. Furthermore, it is clear that the repeatability derived from the analysis of a known volume of sucrose solution is dependent on the laboratory while independent of the thermal protocol used. When performed properly, analysis of standard sucrose solutions can provide a reliable TC calibration procedure. Only three participants showed problems in the within-laboratory consistency, and only one in the betweenlaboratory consistency (Figs. S7, S8).

No clear differences were noticeable between the $z$ scores for EUSAAR2 and NIOSH870, suggesting that poor laboratory performance or deviating results are not protocol specific. The TC repeatability and reproducibility relative standard deviations, 12 and $15 \%$ for EUSAAR2 and 9 and $12 \%$ for NIOSH870, respectively, were at satisfactory levels, taking into account the homogeneity of similar PM sampled HVS filters that ranged from 6 to $10 \%$. All TC standard deviations were found lower for NIOSH870, which may be ex-

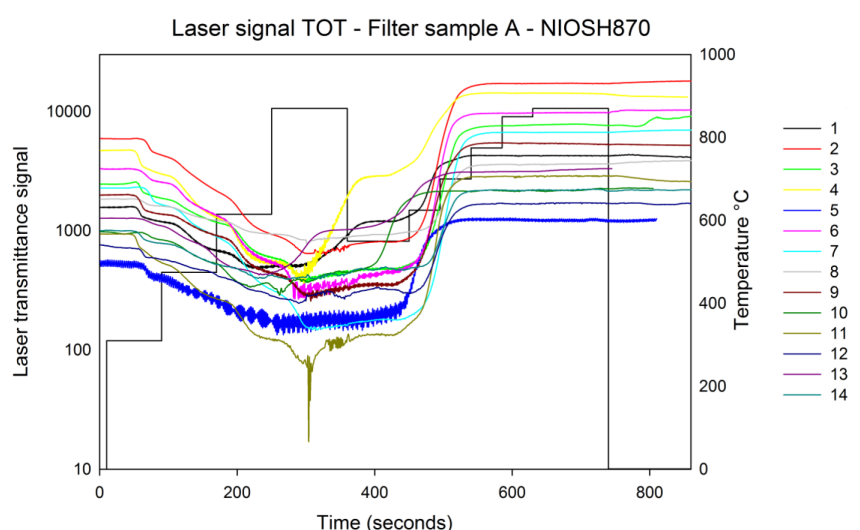

Figure 10. Laser transmittance signal during filter sample A analysis with the use of NIOSH870 thermal protocol for all laboratories.

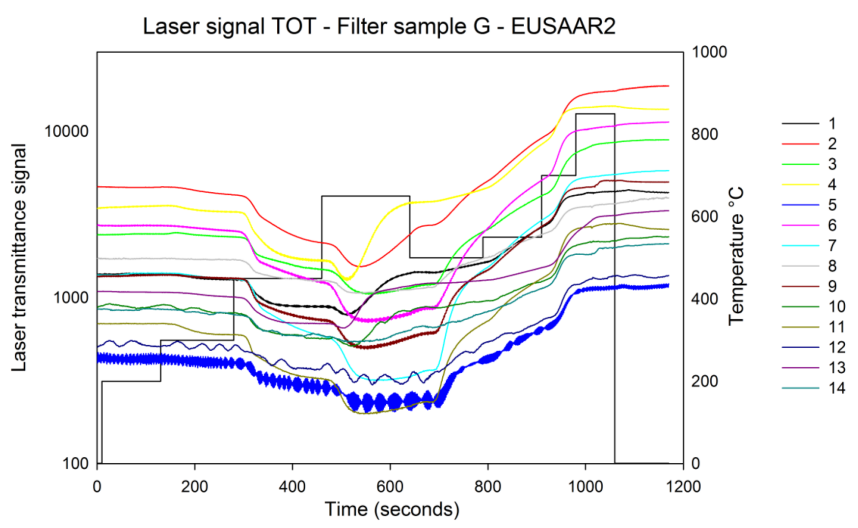

Figure 11. Laser transmittance signal during filter sample $G$ analysis with the use of EUSAAR2 thermal protocol for all laboratories.

plained by the fact that all TC evolved relatively early during analysis while a larger fraction remained present in later steps for EUSAAR2. It may have been the case that a small fraction of TC did not evolve with EUSAAR2 for some samples, possibly those more highly loaded, resulting in greater standard deviations. Nevertheless, the findings of the current exercise showed that after the temperature calibration, almost identical concentrations of TC were measured by both protocols, $\mathrm{TC}_{\text {NIOSH870 }}=0.98 \times \mathrm{TC}_{\text {EUSAAR2 }}\left(R^{2}=1.00\right)$ for robust means.

The EC repeatability and reproducibility relative standard deviations, 15 and $20 \%$ for EUSAAR2 and 20 and $26 \%$ for NIOSH870, respectively, were greater than the TC ones, indicating the additional uncertainties associated with the optical determination of EC. This is supported by the wide range of split points that varied by more than $200 \mathrm{~s}$ for the same sample among different participants. The EC standard deviations were higher for NIOSH870, probably due to the fact that the split point was located on high sections of FID peaks so deviations of a few seconds would have resulted in relatively large changes in the EC amount reported. For EU- 


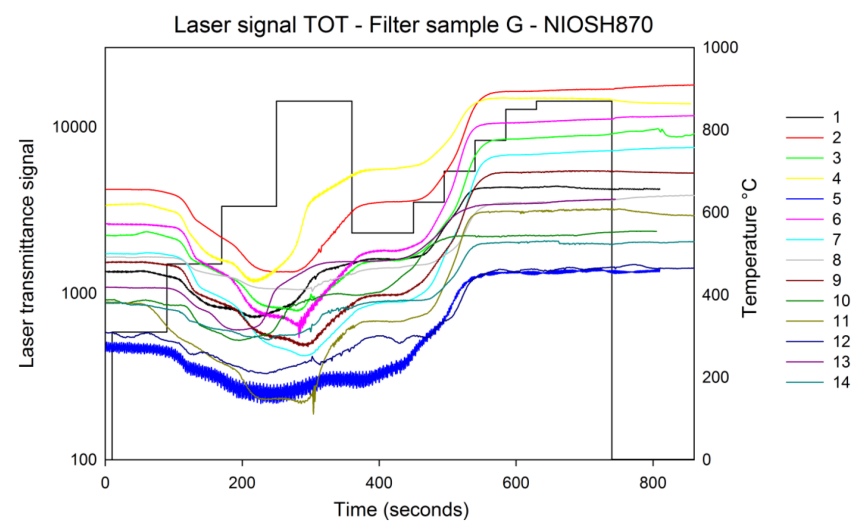

Figure 12. Laser transmittance signal during filter sample $G$ analysis with the use of NIOSH870 thermal protocol for all laboratories.

SAAR2, the split point usually fell in less high sections of FID peaks. Furthermore, the wide range of the laser transmittance signal value for a blank filter, from $\sim 1000$ to $\sim 20000$, may also have affected the capacity of specific instruments to determine the split point accurately. Pre-oxidation resulting in early desorption of POC and EC could also have altered the split point's position.

Based on robust means, TOT EC reported by NIOSH870 is $20 \%$ lower than by EUSAAR2, $\mathrm{EC}_{\mathrm{NIOSH} 870, \mathrm{TOT}}=0.80 \times \mathrm{EC}_{\text {EUSAAR2,TOT }} \quad\left(R^{2}=0.96\right)$. Similar results were found in a comparison performed by GGD Amsterdam, prior to temperature calibration, with $\mathrm{EC}_{\mathrm{NIOSH} 870, \mathrm{TOT}}=0.83 \times \mathrm{EC}_{\text {EUSAAR2, }}$ TOT $\quad\left(R^{2}=0.94\right)$ (Fig. S24 in the Supplement). The above suggests that the temperature offset corrections resulted in no particular improvement in the agreement between thermal protocols. However, the selection of a thermal protocol clearly has an influence on EC analysis and should therefore be stated whenever results are reported, for clarity and comparability.

An additional parameter influencing the EC results is the optical method used. As expected, TOR results were higher than TOT for EC, 64\% higher for EUSAAR2 $\left(R^{2}=0.52\right)$ and $113 \%$ higher for NIOSH870 $\left(R^{2}=0.44\right)$. However, the above values are based on raw data obtained by a limited number of participants that reported both TOR and TOT results, 10 out of a total of 17 . The EC data from the different protocols also varied when applying TOR but in the opposite sense to TOT. More specifically, TOR EC measured with NIOSH870 resulted in higher values by $15 \%$ compared to EUSAAR2, $\mathrm{EC}_{\mathrm{NIOSH} 870, \mathrm{TOR}}=1.15 \times \mathrm{EC}_{\text {EUSAAR2, TOR }}\left(R^{2}=0.95\right)$.

The stability of the calibration area throughout sequential analysis could serve as an additional indicator of robustness of the instrument, since observed deviations are usually caused by gas flow fluctuations, leakages or oven failures. A typical relative standard deviation (\% rSD) of the calibration areas reported throughout an analysis run would be below $5 \%$. Nevertheless, in some cases it was reported to be much higher, mostly due to the fact that analysis was performed on different analysis days (Table 5). In that case, gas flows were shut down at the end of one day and re-adjusted on the following one. It should be noted that gas flows are not strictly defined but have to lie within a suggested range, set manually by the user. The calibration area can also be affected when the calibration gas cylinder is replaced. While the nominal concentration of $\mathrm{CH}_{4}$ in helium is $5 \%$, deviations are possible. A verification of the concentration of the calibration gas is recommended using an independent standard such as a sucrose solution, every time a cylinder is replaced.

When the thermograms were compared across participants, patterns in peak distribution were seen for each sample and protocol used. Overlapping peaks were observed for both protocols but these were not investigated in detail since the focus was mainly given to the EC and OC fractions and not the separate temperature step fractions. Peaks evolving systematically earlier or later may relate to an error in the determination of the transit time of the instrument (Figs. 25). Variations in peak distribution may be the result of absent or inaccurate application of the temperature calibration procedure, or even an indication of possible contamination.

Pre-oxidation is another potential cause of peak distribution differences, which can be verified by the POC concentrations. Low or zero reported POC during analysis may be an indication of oxygen entering the main oven during analysis in the helium phase (Figs. 6-8). Pre-oxidation was identified more clearly during sucrose solution analysis, when peaks evolving in the oxygen phase were small or non-existent and no or low POC was measured (Figs. 4, 5, 8). A possible cause of pre-oxidation may be traces of oxygen present in the helium stream. These can be eliminated by using an in-line oxygen trap.

Leakages, loose connections and oxygen in the helium stream are potential causes of pre-oxidation that may result in a constant presence of oxygen in the instrument during the inert phase of analysis and consequently lead to instrumentspecific systematic deviations. The same effects may also result from sample and/or filter specific properties such as the presence of metals, metal oxides, oxygen donors or other substances that can catalytically affect pyrolytical processes. An example can be seen for the laser transmittance signal values of filter $\mathrm{G}$, where all participants showed signs of preoxidation, which was not the case for the rest of the filters analysed (Figs. 11, 12). The current study gave no indication that the pre-oxidation effect is thermal protocol specific. While such comparison exercises can point out instrument specific pre-oxidation, individual users can also identify it through examination of the laser signal during sucrose solutions analysis. In this case, the laser signal will systematically ramp up during the He phase, caused by the early desorption of POC from the filter.

When the laser transmittance signal was compared among the participants a wide range in the intensity for a blank filter was noted, varying from $\sim 1000$ to $\sim 20000$. However, no 
systematic differences were observed in the determination of the split point after comparing weak signals with stronger ones. High or low frequency noise in the laser signal was identified for a few participants, which can cause a shift in the split point definition.

The NIOSH870 heating profile ramps up to $870{ }^{\circ} \mathrm{C}$ in $360 \mathrm{~s}$ during the helium phase, which appears short and aggressive when compared to EUSAAR2, which ramps up to $650^{\circ} \mathrm{C}$ in $640 \mathrm{~s}$ (Table 2). The POC (TOT) levels were expected to be higher for NIOSH870 after the temperature offset corrections, as observed by Phuah et al. (2009) and Pavlovic et al. (2014). Nevertheless, when POC was compared between the two thermal protocols, NIOSH870 reported generally lower concentrations than EUSAAR2, even for sucrose solutions (Figs. 6-8). A possible explanation could be that lower temperature steps in the inert phase result in more OC exposed during the highest temperature step of the inert phase, and thus more POC formation (Phuah et al., 2009; Pavlovic et al., 2014). Furthermore, the longer residence time of EUSAAR2 on lower temperatures during the inert phase may increase the formation of additional POC compared to NIOSH870.

When the TOT laser signal between the two thermal protocols was compared, no clear difference on the lowest (darkest) point was observed, which is related to POC. This may suggest that not all of the OC was evolved or transformed to POC during the inert phase of EUSAAR2 and some was erroneously measured as POC and EC in the oxygen phase. For the most part, the observations associated with heating profile differences between the two thermal protocols are limited by the number of filters included in the comparison exercise, and further insight would require additional analysis on a wider selection of filters.

EC (TOT) levels were found to be lower for NIOSH870 than for EUSAAR2, explained by the differences in the heating profiles. Considering the fact that almost all analysers in this exercise had to correct their higher temperatures after calibration by significant amounts, it would be expected that different EC values would be reported after the temperature offset corrections than before, for the same analyser and sample. The magnitude of this effect would be instrumentspecific and can only be evaluated by each user independently.

\section{Conclusions}

An ECOC comparison exercise was organized by GGD Amsterdam involving 17 laboratories. Unlike earlier comparison exercises, the participants had to perform a temperature calibration and adjust for offsets prior to analysis, for both EUSAAR2 and NIOSH870 thermal protocols. The offsets ranged from -90 to $+100^{\circ} \mathrm{C}$, varying for each temperature step and instrument, pointing out the necessity of the temperature calibration. The analysis of known volumes of sucrose solutions as well as PM loaded punches of filters functioned as an efficient indicator of erroneous TC calibration and/or laboratory poor performance. Overall, outliers and deviating results were not related to the thermal protocol used.

Reported TC differed on average by only $2 \%$ between EUSAAR2 and NIOSH870 after the implementation of the temperature calibration. EC concentrations differed by a similar ratio to ones observed previously, with $\mathrm{EC}_{\mathrm{NIOSH} 870, \mathrm{TOT}}=0.80 \times \mathrm{EC}_{\text {EUSAAR2, TOT }}\left(R^{2}=0.96\right)$. The TC repeatability and reproducibility (expressed as relative standard deviations) were found to be higher for EUSAAR2 (11 and 15\%) than for NIOSH870 (9.2 and 12\%). Repeatability and reproducibility for EC was found to be lower for EUSAAR2 (15 and 20\%) than for NIOSH870 (20 and 26\%). The formation of POC was found to be higher for EUSAAR2 than for NIOSH870.

Pre-oxidation was identified by low or no POC, or by an increase of the laser signal during the inert phase. Preoxidation was either instrument specific, originating from oxygen present in the system during the inert phase, or sample specific, due to metal oxides and/or oxygen donors present on the sample. Thermograms and laser signal plots obtained within the comparison exercise helped to clearly categorize any pre-oxidation event.

Overall, the current comparison exercise findings are twofold. Firstly, comparison exercises that focus on laboratory performance should be implemented in laboratories' QA/QC procedures in order to reduce the likelihood of systematic errors and/or inaccuracies during ECOC analysis. And secondly, additional operational parameters and protocols should be considered for standardization or reporting, in the same way as temperature offset corrections and standardized thermal protocols have been used in the current study. A list of such parameters would include the initial laser value, POC concentration, calibration area stability, FID and laser signal plots. Actions of that kind can improve the consistency of reported EC and TC results, as well as comparability to surrogates of EC, such as black carbon and black smoke.

\section{The Supplement related to this article is available online at doi:10.5194/amt-8-779-2015-supplement.}

Acknowledgements. The authors would like to thank all laboratories who participated in the current comparison exercise for their kind collaboration. They are particularly grateful to the providers of the HVS samples, Christoph Hüglin (EMPA, Switzerland), Kostas Eleftheriadis (Demokritos, Greece), and the department the Air Quality Monitoring Network of Amsterdam. Finally, they would like to thank Sunset Laboratory for providing the temperature calibration kits and supporting their application.

Edited by: P. Herckes 


\section{References}

Adar, S. D. and Kaufman, J. D.: Cardiovascular disease and air pollutants: Evaluating and improving epidemiological data implicating traffic exposure, Inhal. Toxicol., 19, 135-149, 2007.

Baumgardner, D., Popovicheva, O., Allan, J., Bernardoni, V., Cao, J., Cavalli, F., Cozic, J., Diapouli, E., Eleftheriadis, K., Genberg, P. J., Gonzalez, C., Gysel, M., John, A., Kirchstetter, T. W., Kuhlbusch, T. A. J., Laborde, M., Lack, D., Müller, T., Niessner, R., Petzold, A., Piazzalunga, A., Putaud, J. P., Schwarz, J., Sheridan, P., Subramanian, R., Swietlicki, E., Valli, G., Vecchi, R., and Viana, M.: Soot reference materials for instrument calibration and intercomparisons: a workshop summary with recommendations, Atmos. Meas. Tech., 5, 1869-1887, doi:10.5194/amt-51869-2012, 2012.

Birch, M. E. and Cary, R. A.: Elemental carbon-based method for monitoring occupational exposures to particulate diesel exhaust, Aerosol Sci. Technol., 25, 221-241, 1996.

Cavalli, F., Viana, M., Yttri, K. E., Genberg, J., and Putaud, J.-P.: Toward a standardised thermal-optical protocol for measuring atmospheric organic and elemental carbon: the EUSAAR protocol, Atmos. Meas. Tech., 3, 79-89, doi:10.5194/amt-3-79-2010, 2010.

Cavalli, F., Douglas, K., and Borowiak, A.: Results of the 2nd comparison exercise for EU National Quality Reference Laboratories (AQUILA) for TC, OC and EC measurements, Ispra: Joint Research Center, 2012.

CEN TR 16243: Guide for the measurement of Elemental Carbon (EC) and Organic Carbon (OC) deposit on filters, Brussels: European Committee for Standardization, 2011.

Cheng, Y., Duan, F. K., He, K. B., Zheng, M., Du, Z. Y., Ma, Y. L., and Tan, J. H.: Intercomparison of thermal-optical methods for the determination of organic and elemental carbon: influences of aerosol composition and implications, Environ. Sci. Technol., 45, 10117-10123, 2011.

Cheng, Y., Duan, F. K., He, K. B., Du, Z. Y., Zheng, M., and Ma, Y., L.: Intercomparison of thermal-optical method with different temperature protocols: Implications from source samples and solvent extraction, Atmos. Environ., 61, 453-462, 2012.

Chow, J. C., Watson, J. G., Chen, L. W. A., Arnott, W. P., Moosmüller, H., and Fung, K.: Equivalence of elemental carbon by thermal/optical reflectance and transmittance with different temperature protocols, Environ. Sci. Technol., 38, 4414-4422, 2004.

Chow, J. C., Watson, J. G., Chen, L.-W. A., Paredes-Miranda, G., Chang, M.-C. O., Trimble, D., Fung, K. K., Zhang, H., and Zhen Yu, J.: Refining temperature measures in thermal/optical carbon analysis, Atmos. Chem. Phys., 5, 2961-2972, doi:10.5194/acp5-2961-2005, 2005.

Chow, J. C., Watson, J. G., Chen, L. W. A., Chang, M. C. O., Robinson, N. F., Trimble, D. L., and Kohl, S. D.: The Improve-A temperature protocol for thermal/optical carbon analysis: maintaining consistency with a long-term database, J. Air Waste Manage. Assoc., 57, 1014-1023, 2007.

Chow, J. C., Watson, J. G., Robles, J., Wang, X. L., Cheng, L. W. A., Trimble, D. L., Kohl, S. D., Tropp, R. J., and Fung, K. K.: Quality assurance and quality control for thermal/optical analysis of aerosol samples for organic and elemental carbon, Anal. Bioanal. Chem., 401, 3141-3152, 2011.

Emblico, L., Cavalli, F., Hafkenscheid, T., and Borowiak, A.: Results of the first E/OC comparison exercise for EU National
Air Quality Reference Laboratories (AQUILA), Ispra: Joint Research Center, 2012.

Highwood, E. J. and Kinnersley, R. P.: When smoke gets in our eyes: The multiple impacts of atmospheric black carbon on climate, air quality and health, Environ. Int., 32, 560-566, 2006.

Hitzenberger, R., Petzold, A., Bauer, H., Ctyroky, P., Pouresmaeil, P., Laskus, L., and Puxbaum, H.: Intercomparison of thermal and optical measurement methods for elemental carbon and black carbon at an urban location, Environ. Sci. Technol., 40, 63776383, 2006.

IPCC: Climate Change 2007: Impacts, Adaptation and Vulnerability. Contribution of Working Group II to the Fourth Assessment Report of the Intergovernmental Panel on Climate Change, edited by: Parry, M. L., Canziani, O. F., Palutikof, J. P., van der Linden, P. J., and Hanson, C. E., Cambridge University Press, Cambridge, UK, 976 pp., 2007.

ISO 13528: Statistical methods for use in proficiency testing by inter-laboratory comparisons, ISO, Geneva, 2005.

ISO 5725-2: Accuracy (trueness and precision) of measurement methods and results - Part 2: Basic method for the determination of repeatability and reproducibility of a standard measurement method, ISO, Geneva, 1994.

Jacobson, M. Z.: Strong radiative heating due to the mixing state of black carbon in atmospheric aerosols, Nature, 409, 695-697, 2001.

Janssen, N., Hoek, G., Simic-Lawson, M., Fischer, P., van Bree, L., ten Brink, H., Keuken, M., Atkinson, R., Anderson, H. R., Brunekreef, B., and Cassee, F. R.: Black carbon as an additional indicator of the adverse health effects of airborne particles compared with $\mathrm{PM}_{10}$ and $\mathrm{PM}_{2.5}$, Environ. Health Perspect., 119, 1691-1699, 2011.

Janssen, N., Gerlofs-Nijland, M., Lanki, T., Salonen, R., Cassee, F., Hoek, G., Fischer, P., Brunekreef, B., and Krzyzanowski, M.: Health effects of black carbon, Copenhagen, Denmark: WHO, Regional Office for Europe, 2012.

Lena, S. T., Carter, M., Holguin-Veras, J., and Kinney, P. L.: Elemental carbon and PM2.5 levels in an urban community heavily impacted by truck traffic, Environ. Health Perspect., 110, 10091015, 2002.

Maenhaut, W., Claeys, M., Vercauteren, J., and Roekens, E.: Comparison of reflectance and transmission in EC/OC measurements of filter samples from Flanders, Belgium. Abstract Book of the 10th International Conference on Carbonaceous Particles in the Atmosphere (ICCPA), 26-29 June 2011, Vienna, Austria, Abstract F-6, 2011.

Panteliadis, P.: EC/OC Interlaboratory comparison measurements. 2009 Report, GGD/LO 09-117, Public Health Service Amsterdam, Department of Air Quality, 2009a.

Panteliadis, P.: EC-OC Measurements: Comparison of reflectance and transmittance techniques, GGD/LO 09-1135, Public Health Service Amsterdam, Department of Air Quality, 2009b.

Panteliadis, P.: EC/OC Interlaboratory comparison. 2010 Report, GGD/LO11-1112, Public Health Service Amsterdam, Department of Air Quality, 2011.

Panteliadis, P., Strak, M., Hoek, G., Weijers, E., van der Zee, S., and Dijkema, M.: Implementation of a low emission zone and evaluation of effects on air quality by long-term monitoring, Atmos. Environ., 86, 113-119, 2014. 
Pavlovic, J., Kinsey, J. S., and Hays, M. D.: The influence of temperature calibration on the OC-EC results from a dual optics thermal carbon analyzer, Atmos. Meas. Tech. Discuss., 7, 3321-3348, doi:10.5194/amtd-7-3321-2014, 2014.

Phuah, C. H., Peterson, M. R., Richards, M. R., Turner, J. H., and Dillner, A. M.: A temperature calibration procedure for the Sunset Laboratory carbon aerosol analysis lab instrument, Aerosol Sci. Technol., 43, 1013-1021, 2009.

Piazzalunga, A., Bernardoni, V., Fermo, P., Valli, G., and Vecchi, R.: Technical Note: On the effect of water-soluble compounds removal on EC quantification by TOT analysis in urban aerosol samples, Atmos. Chem. Phys., 11, 10193-10203, doi:10.5194/acp-11-10193-2011, 2011.

Qadir, R. M., Abbaszade, G., Schnelle-Kreis, J., Chow, J. C., and Zimmermann, R.: Concentrations and source contributions of particulate organic matter before and after implementation of a low emission zone in Munich, Germany, Environ. Pollut., 175, 158-167, 2013.

Ramanathan, V. and Carmichael, G.: Global and regional climate changes due to black carbon, Nature Geosci., 1, 221-227, 2008.

Schauer, J.: Evaluation of elemental carbon as a marker for diesel particulate matter, J. Expo. Sci. Environ. Epidemiol., 13, 443453, 2003.

Schauer, J., Mader, B., Deminter, J., Heidemann, G., Bae, M., Seinfeld, H., Flagan, R. C., Cary, R. A., Smith, D., Huebert, B. J., Bertram, T., Howell, S., Kline, J. T., Quinn, P., Bates, T., Turpin, B., Lim, H. J., Yu, J. Z., Yang, H., and Keywood, M.: ACE-Asia intercomparison of a thermal-optical method for the determination of particle-phase organic and elemental carbon, Eviron. Sci. Technol., 37, 993-1001, 2003.
Schmid, H., Laskus, L., Abraham, H. J., Baltensperger, U., Lavanchy, V., Bizjak, M., Burba, P., Cachier, H., Crow, D., Chow, J., Gnauk, T., Even, A., ten Brink, H. M., Giesen, K. P., Hitzenberger, R., Hueglin, C., Maenhaut, W., Pio, C., Carvalho, A., Putaud, J. P., Toom-Sauntry, D., and Puxbaum, H.: Results of the "carbon conference" international aerosol carbon round robin test stage I, Atmos. Environ., 35, 2111-2121, 2001.

Sciare, J., Cachier, H., Oikonomou, K., Ausset, P., Sarda-Estève, R., and Mihalopoulos, N.: Characterization of carbonaceous aerosols during the MINOS campaign in Crete, July-August 2001: a multi-analytical approach, Atmos. Chem. Phys., 3, 1743 1757, doi:10.5194/acp-3-1743-2003, 2003.

ten Brink, H., Maenhaut, W., Hitzenberger, R., Gnauk, T., Spindler, G., Even, A., Chi, X., Bauer, H., Puxbaum, H., Putaud J.-P., Tursic, J., and Berner, A.: INTERCOMP2000: the comparability of methods in use in Europe for measuring the carbon content of aerosol, Atmos. Environ., 38, 6507-6519, 2004.

Wang, Y., Chung, A., and Paulson, S. E.: The effect of metal salts on quantification of elemental and organic carbon in diesel exhaust particles using thermal-optical evolved gas analysis, Atmos. Chem. Phys., 10, 11447-11457, doi:10.5194/acp-1011447-2010, 2010.

Watson, J. G., Chow, J. C., and Chen, L. W. A.: Summary of organic and elemental carbon/black carbon analysis methods and intercomparisons, Aerosol Air Qual. Res., 5, 65-102, 2005.

Zhi, G. R., Chen, Y. J., Sun, J. Y., Chen, L. G., Tian, W. J., Duan, J. C., Zhang, G., Chai, F. H., Sheng, G. Y., and Fu, J. M.: Harmonizing aerosol carbon measurements between two conventional thermal/optical analysis methods, Environ. Sci. Technol., 7, 29022908, 2011. 